\title{
What is Systemic Coaching?
}

\author{
Paul Lawrence \\ Sydney, Australia
}

\begin{abstract}
The term 'systemic coaching' is now widely used, usually to articulate the value for the coach of looking beyond the immediacy of the one-to-one coaching relationship. It is also being used to describe some specific, and quite different, ways of thinking about systems. If coaches are to make sense of this evolving narrative, and to clarify their own individual perspectives, then the industry as a whole must further familiarise itself with relevant thinking from the worlds of management science and organisational development. A necessarily high-level overview of systems theory is presented in this paper, together with illustrations as to how a systemic coaching philosophy might manifest differently when grounded in different ways of thinking about systems. First and second-order systems theories, complexity theories, and theories of complex responsive processes are outlined, ultimately with the objective of enabling coaches to make their own sense of self-as-systemic-coach.
\end{abstract}

Keywords: coaching, systemic coaching, systems thinking, systemic, systematic

\section{Introduction}

The term 'systemic coaching' is becoming increasingly popular, the term often used as if it represents a single philosophy. The relatively recent emergence of the term has accompanied a new level of reflection on the complexity of the world today. As Hofkirchner and Rousseau (2015) put it:

The crises we face are systemic in nature. To overcome those crises we need to understand how systems work. To arrive at such an understanding we need to think systemically.

Whilst becoming more popular, the term 'systemic coaching' is used to represent different approaches to coaching, often without a detailed explanation of how the term is being used, the philosophical underpinnings of the particular definition, or a comparison to other uses of the term. There is a risk that the term 'systemic coaching' becomes appropriated by a plethora of practitioners, some of whom using the term to describe approaches that lack substance or

This is an Open Access article distributed under the terms of the Creative Commons Attribution (CC BY) License which permits use, distribution and reproduction in any medium, provided the original work is properly cited. 
grounding. Indeed, systemic coaching may become the new neuro-leadership, an example of "pop-science band-wagoning" (Grant, 2015). The purpose of this paper is not to critique existing narratives. Instead the aim is to lay out at a necessarily high level the development of thinking in the systems thinking domain, in particular how it has been interpreted by the organisational development community and others working in the management sciences. This is a specific field of enquiry that has been active for more than 60 years but has yet to be fully embraced by the coaching community. It is the purpose of this paper to layout some key themes in the area of system thinking, not in service of commending a particular approach or philosophy, but to stimulate further dialogue as to how theories of systems thinking may be most usefully applied in the coaching domain and to begin to illustrate how different systems philosophies may manifest differently in practice.

The coaching community is not the first to encounter the challenge of making visible the similarities and differences between different uses of the term 'systemic'. Lane and Jackson (1995) said of the systems thinking community generally:
Using the term 'systems thinking' in a way which is both imprecise and, apparently, unaware of intellectual antecedents also has the effect of blurring the boundaries between different approaches." And the “... usage of the term 'systems thinking' is spreading in the SD (systems dynamics) community with an enthusiasm which verges on the hegemonic. The employment of this term to describe our own single methodology is virtually to deny the existence of any other, if we use that term for our own discipline, we are putting ourselves in a mental prison.

In this paper a high-level overview of systems theory is presented, followed by some specific examples to illustrate how the same term may be used to describe quite different approaches to coaching. Key points of difference between these approaches are then identified which, it is hoped, will enable both effective comparison both between and within different philosophies, and a critique of methodologies claiming to represent established schools of thought.

Three uses of the term 'systemic' are cited here in order to illustrate how idiosyncratic the phrase 'systemic coaching' may become. None of these three usages is being criticised (indeed one is the author's own), rather the three approaches are detailed to illustrate how different they are from each other. First, Whittington (2012) defines systemic coaching as "that which acknowledges, illuminates and releases the system dynamics so that each 
element can function with ease." Systems dynamics are defined as the outcome of interactions between forces that exist between parts in a system, a system being defined as a set of interacting or interdependent entities forming a whole. The purpose of systemic coaching is to identify the 'truth' of the system and to restore 'system coherence' so that people in the system understand their place and are free to operate at their best. Whittington's book focuses on the application of a particular technique, called constellations work. A constellation is defined as a practical intervention, the objective of which is to illuminate invisible dynamics behind relationship difficulties, stuck issues and challenges. The creation of a constellation enables participants to identify patterns and dynamics in service of resolving issues.

As will become clear, this appears to be an example of first-order systems thinking. Clutterbuck (2007) contrasts 'thinking systematically' with 'thinking systemically'. To think systemically is to take a holistic approach that recognises the organisation to be a complex entity, comprising interconnected parts. It is a way of thinking that helps coach and coachee avoid engaging in over-simplistic analyses and coming up with over-simplistic solutions. Clutterbuck's perspective is defined in less detail than is Whittington's, but appears to eschew aspects of first-order thinking and commend an approach based on second-order systems thinking or complexity theory. Lawrence (2015) suggests that systemic coaching is not about a particular set of skills or techniques, rather it is a mindset, that includes a belief in the significance of 'authentic reflective dialogue'. Dialogue is defined with reference to the work of Bohm (1996) and Isaacs (1999), and the author makes explicit reference to Stacey's notion of 'complex responsive processes' and to his rejection of the idea that practitioners can successfully stand outside an organisation system and diagnose it as if it were a system (Stacey, 2012; Stacey \& Mowles, 2016).

These three perspectives on systemic thinking are quite different, but identifying where they are different and where they similar is not straightforward without reference to a broader perspective on systems thinking. Consequently, it is likely that practitioners, and others in the industry, may be becoming increasingly confused as to what the word 'systemic' means in the context of coaching.

\section{Systems theories}

A spate of papers on systems thinking were published in the 1950 s, by biologists, economists and engineers (Stacey \& Mowles, 2016). Three strands of thinking; general systems theory, cybernetic systems and systems dynamics 
co-evolved, and these ideas and philosophies began to permeate other disciplines, including management theory. From these three schools of thought emerged other ideas, including Living Systems Theory (Miller, 1978; Bailey, 2005), autopoiesis (Varela, Maturana \& Uribe, 1974), Soft Systems Methodology (Checkland, 1994, 2000, 2012; Checkland \& Haynes, 1994), Critical Systems Thinking (Ulrich, 2003), chaos theory (Gleick, 1988), complexity theory (Gell Mann, 1994), Complex Adaptive Systems (Marion \& Uhl-Bien, 2001) and within each of these theories there exist significant variations on a theme. Space does not permit a thorough articulation of each of these theories. Instead four theories will be presented in service of isolating key points of difference, an understanding of which may help coaches identify their own particular philosophy as to what it means to be a systemic coach, and to question and challenge others who talk about being systemic. These four theories will be loosely referenced to a typology borrowed from Stacey and Mowles (2016).

\section{First-order systems theories}

Ludwig von Bertalanffy (1969) was an Austrian biologist who developed a general systems theory in response to the inadequacy of purely mechanistic theories to address theoretical problems, particularly in the biosocial sciences. He noted that whilst the physicist, the biologist, psychologist and social scientists were focused on their own areas of study, they seemed to be working on similar problems. General Systems Theory (GST) is an attempt to identify universal principles that apply across different fields of study (Amerikaner, 1981; Caws, 2015; Malecic, 2017; Rousseau, 2015; Schneider \& Somers, 2006). A major contribution of GST was to switch attention to the functioning of open systems. Physical chemistry, up until that time, had tended to focus on closed systems, operating in isolation of their surrounding environments. Some first-order systems, for example first-order cybernetics, also modelled closed systems (Bateson, 1967; Guy, 2018; Lepskiy, 2018; Schwaniger, 2015; Scott, 2016; Stacey \& Mowles, 2016). Open systems, by contrast, maintain themselves through a continuous exchange of components in and out of the system, across boundaries. These systems are self-regulating, with equilibrium maintained by forces acting to dampen the effect of disturbance from outside. Whilst Bertalanffy believed that social systems were subject to these same systemic principles as other systems, he recognised that they were very complicated, such that the system could only be understood in terms of general principles. He sought to model the activity of open systems through the use of mathematical models, on the basis that statistical averages could adequately represent the activity of 'incalculable unknown processes'. GST, Bertalanffy 
said, is a 'logico-mathematical science of wholeness', seeking to develop future insights through the application of mathematics.

From this brief description of GST we can identify three underlying assumptions that will serve to contrast first-order systems thinking from other schools of thought. First, it is assumed that a social system is a real system, like a machine, or a living organism. Second, it is assumed that the operation of a first-order system is ultimately logical and can be modelled mathematically. Third, it is assumed that the external observer can stand outside the system, diagnose its functioning, and design interventions that will control its future operation.

\section{First-order systems thinking in the coach}

A coach operating to first-order principles is likely to regard organisational systems as real, and to think in terms of boundaried sub-systems. The coach is unlikely to look often beyond linear cause-and-effect and will search out such relationships when presenting scenarios appear complicated. Consistent with first-order cybernetic principles, change will be regarded as the exception to the norm, and the purpose of coaching may be to move or return to a predictable form of equilibrium. The coach may tend to talk about the organisation as if coach and coachee can usefully position themselves outside the system, in service of coming up with interventions designed to shift the functioning of the system at a macro-level. Watching such a coach in action we might see the coach encouraging the coachee to collect data and information in service of creating a full and comprehensive understanding of the way the organization works. Conversation is likely to focus on enhancing or upgrading component parts of the system in the belief that the performance of the system as a whole will inevitably improve if the quality of the parts is upgraded. This is analogous to organisation-as-machine; if my car will not start then I must identify which part of the engine needs to be mended or replaced. In an organisational setting this might mean motivating particular individuals or otherwise focusing on individual performance. Feedback is therefore important in enabling individuals to perform more effectively. Coach and coachee may come up with medium/long term coaching plans or seek to address strategic uncertainty in the business again by means of medium/long term planning.

\section{Second-order systems theories}

With reference to GST, Checkland (2000) believes that attempts to identify general rules, that may be mathematically modelled and applied to all 
systems, have failed. They have failed because the world is seen to be too "complex, problematical and mysterious". The first two assumptions underlying first-order systems thinking are therefore challenged, namely the assumptions that a social system is usefully regarded as a real system, and second that the operation of a social system can be modelled mathematically. Gregory Bateson expressed a similar view in suggesting that people can never perceive reality directly, that they perceive only a personal representation of reality (Hawkins, 2004; Kobayashi, 1988). The organisation as system can thus only usefully be regarded as a metaphor, and it must be acknowledged that different people will conjure up different metaphors based on their individual perception of the organisation. Instead of thinking of the world as a set of systems therefore, it is better to construct a systemic process of inquiry (Atkinson \& Checkland, 1988; Checkland, 1994, 2000, 2012; Checkland \& Haynes, 1994). In other words, in first-order thinking systemicity is assumed to be in the world, whereas through the lens of Soft Systems Methodology (SSM) systemicity is assumed to be an aspect of process through which we engage with the world.

Stacey (2012) critiques the evolution of his own systems thinking and regrets the popularity of one of his models. He refers to the second edition of 'Strategic Management and Organisational Dynamics' in which he presented a chart with two axes, charting levels of certainty against level of agreement between people. High levels of certainty and agreement indicated stability and predictability, which validated the use of standard management tools. Low levels of certainty and agreement represented anarchy and necessitated alternative approaches. The model is quite similar to the well-known Cynefin model (Snowden \& Boone, 2007). Both models invite the outside observer to diagnose the system and determine the nature of an effective intervention. The problem with both models from a second-order perspective, is that they imply that an individual is able to stand outside the system and make an objective assessment of what is happening in the system.

The development of SSM was marked by three key ideas (Atkinson \& Checkland, 1988; Checkland, 1994, 2000, 2012; Checkland \& Haynes, 1994). These are:

- All problems are situations in which people are trying to take purposeful action.

- Different people have different perspectives on a situation, and therefore different versions of what needs to happen next. 
- Therefore, people need to work together to come up with a working model of the system, in service of coming up with a plan of action, and they need to learn together from the application of the model.

SSM is built upon these three key ideas. Application of an SSM entails i) a consideration of a real-world problem ii) the formulation of models to depict the problem in the form of systems iii) an inquiry of the problem using the model as a source of questions iv) the identification of actions.

The main difference then between first and second order systems thinking, working with social systems, is the extent to which it is appropriate to regard the social system as a real system. What both approaches have in common is the idea that the leader or coach is able to stand outside the system, alone or with others, and conduct some form of diagnosis in service of coming up with the solution to a problem.

\section{Second-order systems thinking in the coach}

A second-order systemic coach is unlikely to regard the coachee's perspective on an issue as a single truth. The coach will be curious as to what other people in the system are thinking, and through what lenses they are observing events. The coach will encourage the coachee to engage with others, to seek out different perspectives and to integrate those perspectives in seeking to further understand events. Because the coach regards the organisation as 'complex, problematical and mysterious', the coach will encourage the coachee to experiment and to reflect on the outcomes of actions taken. Such coaches are, moreover, conscious of the subjectivity of their own perspectives. They seek to enhance those perspectives through collaborative reflective practice. Watching such a coach in action we may see the coach encouraging coachees to explore their own mental models, and the mental models of others in organisation. The coach is likely to hold their own hypothesis as to how the organisation is operating 'lightly', and encourages the coachee to do the same.

\section{Complexity theories}

There are a multitude of different complexity theories. Complex Adaptive Systems (CAS) theory is one form of complexity theory, and there are multiple interpretations of CAS (Gell Mann, 1994; Schneider \& Somers, 2006). Many complexity theories are not fundamentally dissimilar from first and/or second order systems thinking, in that they appear to assume that an organisation may be regarded as a real system and/or that the organisation as system can be diagnosed and understood and interventions plotted from outside. Stacey and 
Mowles (2016) suggest that chaos theory and theories of dissipative structures, both complexity theories, are similar to first and second order systems thinking in that they focus on the macro and offer little insight as to the detailed mechanics underlying organisational function, a focus on the micro that is fundamental to other complexity theories.

Where both theories are useful, he suggests, is in introducing the notion of stable instability, or unstable stability. Mathematicians found that systems dynamics models produced wholly predictable patterns within certain parameters. These patterns are referred to as 'attractors'. Within other parameters the system becomes disorganised. In between stability and disorganisation is a pattern that looks random, but on closer examination is not. This pattern is called a 'strange attractor' or 'fractal'. This is a dynamic in which stability and instability are both present. The pattern is apparently chaotic, but the apparent chaos belies a state of order, it is just that the pattern of activity is highly unusual. These mathematical models have been used to explain weather systems, a good example of stable instability. We may complain how unpredictable is the weather, but we know it never snows on Bondi Beach or in the Sahara Desert. In other words, whilst someone living in Sydney may not know whether it is going to rain tomorrow (unpredictable), they do know they will not be building snowmen (predictable). This idea of predictable unpredictability takes systemic thinking to another place, away from a preoccupation with equilibrium to a consideration of the necessary conditions for change. Applying these theories to organisations is to advocate a movement toward 'chaos', because it is only in this state of stable instability that change happens, and most organisations want to achieve some sort of change.

Though there exist multiple perspectives of CAS, most theories align around common principles (e.g. Boal \& Schultz, 2007; Cavanagh, 2006; Kamo $\&$ Phillips, 1997). The focus is on the micro rather than the macro. Instead of assuming that agents in a system are passive, or that we can somehow assume an average level of activity, agents in a complex adaptive system are assumed to be operating to local rules. Local agents interact with each other and with their environment and from those interactions emerge aggregate behaviours. Local sub-systems are then subject to feedback from these aggregated behaviours and respond to it. Interaction at the local level continues to evolve as local agents seek to survive in the environment provided by all the parts of the system, and local rules emerge anticipating responses to the wider environment. 
Some writers have illustrated these principles with reference to the flocking of birds. Each bird may be operating according to a rule that says, for example, fly alongside and slightly behind one of your fellow birds, and if there are already twenty birds in line, drop back and fly behind a fellow bird etc. There is no overall blue-print and the birds are not attempting to fly in formation. The shape of the flock is an outcome of the behaviour of individuals, each adhering to a simple rule. The flocking of birds illustrates a basic principle of CAS but is not a good metaphor for the functioning of CAS in an organisational setting, because in an organisation each individual or sub-system is likely to be operating to its own specific and dynamic set of rules. In other words, what flying pattern would emerge if each bird, or small group of birds, was operating to a different simple rule, a rule which shifted and changed? The emerging pattern would be both unpredictable and dynamic.

This perspective on a system renders absurd the notion of the external practitioner standing outside the system, plotting its future trajectory. For even if the diagnosis is conducted by a group of people, all recognising the limitations of their own perspectives and working in collaboration, this group is but one sub-system in the whole, and there will be other individuals and groups having similar and yet different conversations. Each group will encounter other groups in its local vicinity, and from those interactions will emerge something unpredictable.

\section{Complexity thinking in the coach}

The coach believes it is important to look beyond the behaviour of the individual in order to understand events. The coach is curious as to the nature of local interactions, and the convergence of different schools of thought across the organisational system. The coach will be interested, above all, in seeking to understand interpersonal dynamics, and will take advantage of any opportunity to personally witness social interactions. The coach searches for tensions in the system, recognising that change tends to emerge in conditions of ambiguity and uncertainty. The coach may express little interest in drawing detailed plans, believing that change tends to emerge and that efforts to direct change in a particular direction over a period of time ae unlikely to succeed. Watching such a coach in practice, we might observe the coach encouraging the coachee to challenge the mindset that suggests leaders can control outcomes. The coach will focus above all on social interaction, and the nature of that interaction, and on the emergence and evolution of social identity and power dynamics. The coach is fully aware that their own behaviour and utterances are as much a part of the system as any other agent in the organisational environment. The coach's 
behaviour will be informed by that understanding and by an ongoing attunement to changes in the environment.

\section{Complex responsive processing}

There are many different versions of complexity thinking, most focusing on the behaviour of individual agents, or sub-systems. To further their understanding of complex systems, mathematical modelers assign rules to individual agents and observe the outcome of the interaction between those agents. But how applicable is this approach in seeking to understand the behaviour of social systems, where the individual unit is a human being or a collective of human beings? Human beings are not flocking birds, all acting in accordance with standard simple rules. Human beings are conscious, emotional and spontaneous, capable themselves of observing the pattern of interactions within which they are operating and responding accordingly. People think about their work, are often bored by repetition, seek novelty, dislike being told what to do, and may seek to avoid change (Suchman, 2011). In this sense human beings, and the interactions between human beings, may be un-modellable, and the system metaphor may not actually be very useful (Bovaird, 2008; Stacey \& Mowles, 2016; Suchman, 2011).

Stacey and Mowles (2016) suggest it is most useful to focus on the responsive manner in which humans interact with each other, an approach they label 'complex responsive processing'. Through this lens no-one can control the functioning of the whole. The role of the leader is to engage intentionally and skillfully in local interaction, responding in the moment to events as they emerge. Whilst we can still talk about the functioning of human systems, ideas from systems thinking that imply some level of logical or rational relationship between entities, may not work for the student of social systems in the same way they may work better for the student of physics or engineering. The systems metaphor in this case may be less useful than confusing, in terms of implying the possibility of objective diagnosis and management control. Stacey's thinking on complex responsive processes is very much influenced by the work of the sociologist Norbert Elias. Elias argued that the notion of society as a whole, serves as an interesting abstraction but does not reflect the dynamic nature of human social life, with all its contradiction, tension, and unpredictable localised interaction. Social order in this sense, is not a stable equilibrium to which people are subject, rather it is a dynamic, ever-changing, unpredictable outcome of local interactions. This is not to say that the evolution of social order is random, for human beings do not operate independently. Human beings are social creatures who both enable and restrain the behaviour of other human 
beings. Along similar lines, Suchman (2011) contrasts the value of regarding the organisation as a machine vs regarding the organisation as a collective conversation. The latter metaphor discourages us from thinking about the organisation as a reified object. It encourages us to notice self-organising patterns of thinking and relating, and to encourage the same perspective taking in others. Boal and Schultz (2007) suggest that strategic leaders best fulfil their roles through dialogue and storytelling, by which means they are able to shape the evolution of agent interactions and facilitate the emergence of collective shared meanings. Baskin (2008) invites us to substitute the idea of complex adaptive systems for the idea of storied spaces, places where groups of people come to together to negotiate meaning. With reference to this perspective on change, Blomme (2012) lists six implications for effective leadership.

\section{Complex responsive thinking in the coach}

A complex responsive coach is likely to believe in the limitations of a systemic approach, in particular the idea that we can place boundaries around and within a system, and the idea that people's behaviours are controllable and/or predictable. The coach sees the organisation as a complex myriad of ever-shifting, dynamic and evolving relationships. The role of a leader is not to try and direct events, but to knowingly and purposefully participate in relationships in service of influencing the behaviour of others. The coach will pay attention to the enactment of power dynamics and the evolution of collective social identity. We might observe the coach encouraging the coachee to notice management efforts to direct and control outcomes and to hold lightly demands to implement change. Coach and coachee may explore the notion of identity, at the level of the individual and the collective, and notice how differences in identity manifest themselves and are addressed by those seeking to implement change. The coach will encourage the coachee to pay attention to quality of conversation, with reference perhaps to models of monologue and dialogue, and to become further aware of their own patterns of thinking and relating.

\section{Implications for practice}

In sharing some of these ideas over recent months with fellow coaches and academics, I have recognised an implicit assumption in others that these four perspectives on systems thinking constitute a linear pathway toward a more sophisticated and desirable coach practice model. Accordingly, I have been asked what value there is in spending time outlining how first- and second- order perspectives may manifest themselves in coaching? Why not 
instead focus on advocating complex systemic and/or complex responsive perspectives, and on providing case studies to illustrate how such perspectives translate into practice? This is a great challenge, and I will endeavour to respond to it in future writings, but the purpose of this paper is different. The purpose of this paper is to compare and contrast perspectives and to provide a simple framework through which practitioners can query and otherwise explore different manifestations of 'systemic coaching'.

The framework is necessarily simplistic. It is not being suggested that there exist 'first order systemic' coaches, 'second order systemic' coaches, 'complex systemic' coaches and 'complex responsive' coaches. Coaches are discouraged from categorising themselves in this way. The coach may more usefully invest time in querying their own coaching 'philosophy' (Jackson \& Bachkirova, 2019) in service of further clarifying for themselves their personal relationship with systems thinking. Similarly, in interpreting specific accounts of systemic coaching, it is unlikely that particular theories can be neatly classified under one of these four headings. The value of the framework lies in enabling the practitioner to discern the philosophy of the writer and to question the alignment of theory and practice.

Table 1 compares and contrasts some fundamental beliefs underlying each of the four hypothetical perspectives. Some coaches may readily identify with one of the four perspectives. Others may find themselves picking and choosing from different perspectives. This should not be surprising given the simple nature of the framework. The exercise is valuable, it is suggested, in prompting a more in-depth consideration of personal philosophy. 
Table 1. Beliefs underpinning four hypothesised perspectives

\begin{tabular}{llll}
\hline \multicolumn{1}{c}{$\begin{array}{c}\text { First order } \\
\text { systemic }\end{array}$} & \multicolumn{1}{c}{$\begin{array}{c}\text { Second order } \\
\text { systemic }\end{array}$} & \multicolumn{1}{c}{$\begin{array}{c}\text { Complex } \\
\text { systemic }\end{array}$} & \multicolumn{1}{c}{$\begin{array}{c}\text { Complex } \\
\text { responsive }\end{array}$} \\
\hline $\begin{array}{l}\text { Organisational systems } \\
\text { are real. }\end{array}$ & $\begin{array}{l}\text { Organisational systems } \\
\text { are real. }\end{array}$ & $\begin{array}{l}\text { Organisational systems } \\
\text { are real. }\end{array}$ & $\begin{array}{l}\text { Organisations are not } \\
\text { systems. }\end{array}$ \\
\hline $\begin{array}{l}\text { Systems can be broken } \\
\text { down into component } \\
\text { parts. }\end{array}$ & $\begin{array}{l}\text { Systems are complex, } \\
\text { problematical and } \\
\text { mysterious. }\end{array}$ & $\begin{array}{l}\text { To understand the } \\
\text { functioning of the } \\
\text { whole system requires } \\
\text { an exploration of local } \\
\text { interactions. }\end{array}$ & $\begin{array}{l}\text { The nature of human } \\
\text { interaction is too } \\
\text { unpredictable and } \\
\text { responsive to be } \\
\text { modelled. }\end{array}$ \\
\hline $\begin{array}{l}\text { Underlying principles } \\
\text { and rules can be } \\
\text { discerned. A leads to B } \\
\text { leads to C. }\end{array}$ & $\begin{array}{l}\text { Underlying principles } \\
\text { and rules can be } \\
\text { hypothesised }\end{array}$ & $\begin{array}{l}\text { Systemic patterns } \\
\text { emerge through social } \\
\text { interaction. }\end{array}$ & $\begin{array}{l}\text { Relational patterns } \\
\text { emerge through social } \\
\text { interaction. }\end{array}$ \\
\hline $\begin{array}{l}\text { It is possible to stand } \\
\text { outside a system and } \\
\text { diagnose its functioning. }\end{array}$ & $\begin{array}{l}\text { It is possible to stand } \\
\text { outside a system and } \\
\text { diagnose its functioning. }\end{array}$ & $\begin{array}{l}\text { Every agent in the } \\
\text { system plays a role in } \\
\text { the emergence of } \\
\text { outcomes. }\end{array}$ & $\begin{array}{l}\text { The organisation is not } \\
\text { a system but is part of } \\
\text { a wider myriad of } \\
\text { social relationships. }\end{array}$ \\
\hline
\end{tabular}

In Table 2, the four perspectives are compared and contrasted in respect of their translation into practice. Again, the purpose of the framework is to prompt coaches into questioning the way that they coach. This is 'process' according to Jackson and Bachkirova (2019) and it is useful to compare philosophy and process. Is the way I personally coach consistent with my espoused beliefs? Are the processes espoused by particular writers consistent with underlying theory?

The purpose of this paper is not to encourage practitioners to begin categorising themselves, other coaches, and writers, into one of four boxes. Rather it is to offer a simple framework/language to enable practitioners to talk about different aspects of systemic practice, a dialogue from which may emerge new insights as to how the industry generally might continue to adapt to a world that continues to evolve and change at a rapid pace. 
Table 2. Practices associated with four hypothesised perspectives

\begin{tabular}{|c|c|c|c|}
\hline \multicolumn{4}{|c|}{ Systemic Perspective } \\
\hline $\begin{array}{l}\text { First order } \\
\text { systemic }\end{array}$ & $\begin{array}{l}\text { Second order } \\
\text { systemic }\end{array}$ & $\begin{array}{l}\text { Complex } \\
\text { systemic }\end{array}$ & $\begin{array}{l}\text { Complex } \\
\text { responsive }\end{array}$ \\
\hline $\begin{array}{l}\text { Collect data (e.g. } \\
\text { organisation charts) to } \\
\text { understand how the } \\
\text { system works. }\end{array}$ & $\begin{array}{l}\text { Seek to understand } \\
\text { multiple perspectives on } \\
\text { organisation-as-system. }\end{array}$ & $\begin{array}{l}\text { Seek to understand } \\
\text { patterns of local } \\
\text { interaction and how } \\
\text { local interactions } \\
\text { converge into wider } \\
\text { patterns of behaviour. }\end{array}$ & $\begin{array}{l}\text { Seek to understand } \\
\text { patterns of social } \\
\text { interaction. Holding the } \\
\text { idea of system } \\
\text { boundaries lightly. }\end{array}$ \\
\hline $\begin{array}{l}\text { Focus on upgrading } \\
\text { component parts e.g. } \\
\text { individual leader } \\
\text { performance, individual } \\
\text { motivation etc ... }\end{array}$ & $\begin{array}{l}\text { Focus on mental models } \\
\text { (self and others). }\end{array}$ & $\begin{array}{l}\text { Focus on patterns of } \\
\text { local interaction. }\end{array}$ & $\begin{array}{l}\text { Focus on patterns of } \\
\text { social interaction and } \\
\text { the emergence of } \\
\text { identity and power } \\
\text { dynamics. }\end{array}$ \\
\hline $\begin{array}{l}\text { Collect feedback to } \\
\text { enhance individual } \\
\text { performance. }\end{array}$ & $\begin{array}{l}\text { Collect feedback to } \\
\text { deepen understanding of } \\
\text { system functioning. }\end{array}$ & $\begin{array}{l}\text { Collect feedback to } \\
\text { deepen understanding } \\
\text { of system functioning at } \\
\text { the micro-level. }\end{array}$ & $\begin{array}{l}\text { Collect feedback to } \\
\text { deepen understanding } \\
\text { of patterns of social } \\
\text { interaction. }\end{array}$ \\
\hline $\begin{array}{l}\text { Focus on building plans } \\
\text { and agreeing strategy. }\end{array}$ & $\begin{array}{l}\text { Consider plans and } \\
\text { strategies as ongoing } \\
\text { hypotheses. Be ready to } \\
\text { adapt and change. }\end{array}$ & $\begin{array}{l}\text { Consider plans and } \\
\text { strategies as local } \\
\text { responses to changes in } \\
\text { the system. }\end{array}$ & $\begin{array}{l}\text { Consider plans and } \\
\text { strategies as local } \\
\text { responses to wider } \\
\text { patterns of social } \\
\text { interaction. }\end{array}$ \\
\hline
\end{tabular}

\section{Conclusions}

More and more coaches, coach training houses, and authors are advocating a more systemic approach to coaching. Most of these voices urge both coach and leader to look beyond the dyadic relationship between coach and coachee, and interpersonal relationships within a team, to consider the impact of other variables in the 'system'. The system metaphor, however, can be used to depict quite different approaches to working with clients. First-order approaches depict the organisation as a coherent system operating to a set of rules. The coach and the manager can view the system from without and decide what changes they will make to the organisation for it to be more effective. Second-order approaches recognise that organisations are not tangible systems, rather they are mental constructs, and that it is therefore necessary to challenge the perspective of the outside observer. Approaches based on theories of CAS 
pay attention to local interaction and view broader patterns of behaviour as an outcome of myriad local interactions. The complex responsive perspective recognises the limitation of the system metaphor and focus on patterns of local interaction.

Change within the organisation as a whole is an outcome of all the multiplicity of local interactions taking place within it. These are four quite different philosophies, and because these perspectives on system are so different, it may be useful for us to make meaning of different systems approaches as we, the coaching industry, work out between us how we can be most useful in contributing to the success of organisations and society as a whole. In doing so, it may be useful for us to refrain from aligning ourselves too closely with a particular perspective and recognise that all four perspectives may prove useful when regarded as metaphor and deployed in different contexts. To focus instead on advocating a favourite perspective as being truly 'systemic' is to encourage convergence, at a time when we may more usefully engaged in a dialogic exploration of philosophies and perspectives that are different to our own.

\section{References}

Amerikaner, M. J. (1981). Continuing Theoretical Convergence: A General Systems Theory Perspective on Personal Growth and Development. Journal of Individual Psychology, 37(1), 31-53

Atkinson, C.J. \& Checkland, P. (1988). Extending the Metaphor "System". Human Relations, 10, 709-725

Bailey, K. (2005). Beyond System Internals: Expanding the Scope of Living Systems. Systems Research and Behavioral Science Systems Research, $22,497-508$

Baskin, K. (2008). Storied Spaces: The human equivalent of complex adaptive systems. Emergence: Complexity and Organization, 10(2), 1-12

Bateson, G. (1967). Cybernetic Explanation. The American Behavioral Scientist, 10(8), 29-32

Bertalanffy, L. von. (1968). General Systems Theory. USA: George Braziller.

Blomme, R.J. (2012). Leadership, Complex Adaptive Systems, and Equivocality: The Role of Managers in Emergent Change, Organization Management Journal, 9(1), 4-19

Boal, K. \& Schultz, P.L. (2007). Storytelling, Time, and Evolution: The role of strategic leadership in complex adaptive systems. The Leadership Quarterly, 18, 411-428

Bohm, D (1996). On Dialogue. Routledge, London 
Bovaird, T. (2008). Emergent Strategic Management and Planning Mechanisms in Complex Adaptive Systems. The Case of the UK Best Value initiative. Public Management Review, 10(3), 319 - 340

Cavanagh, M. (2006). Coaching from a Systemic Perspective: A complex adaptive conversation. In: D.R. Stober \& A.M. Grant, (Eds.), Evidence Based Coaching Handbook: Putting best practices to work for your clients. NJ: John Wiley \& Sons

Caws, P. (2015). General Systems Theory: Its Past and Potential. Systems Research and Behavioral Science Systems Research, 32, 514-521

Checkland, P. (1994). Systems Theory and Management Thinking. The American Behavioral Scientist, 38(1), 756-791

Checkland, P. (2000). Soft Systems Methodology: A Thirty Year Retrospective. Systems Research and Behavioral Science, 17, S11-S58

Checkland, P. (2012). Four Conditions for Serious Systems. Systems Research and Behavioral Science, 29, 465-469

Checkland, P. \& Haynes. M. (1994). Varieties of Systems Thinking: the case of Soft Systems Methodology. Systems Dynamics Review, 2/3, 189-197

Clutterbuck, D. (2007). Coaching the Team at Work. London: Nicholas Brealey International

Gell Mann, M. (1994). Complex Adaptive Systems. In: Complexity: Metaphors, Models and Reality. G. Cowan, D. Pines, D. Meltzer (Eds.). NY: Perseus

Gleick, J. (1988). Chaos: The making of the new science. London, UK: William Heineman

Grant, A.M. (2015). Coaching the brain: Neuro-science or neuro-nonsense? The Coaching Psychologist, 11(1), 31-37

Guy, J. (2018). Niklas Luhmann before Relational Sociology: The Cybernetics Roots of Systems Theory. Systems Research and Behavioral Science, $35,856-868$

Hawkins, P. (2004). A centennial tribute to Gregory Bateson 1904-1980 and his influence on the fields of organizational development and action research. Action Research, 2(4), 409-423

Hofkirtchner, W. \& Rousseau, D. (2015). Foreword to: L. von Bertalanffy. General Systems Theory, revised edition. USA: George Braziller.

Isaacs, W (1999). Dialogue and the Art of Thinking Together. NY: Currency Doubleday

Jackson, P. \& Bachkirova, T. (2019). The 3 Ps of supervision and coaching: Philosophy, Purpose and Process. In: E. Turner \& S. Palmer, (Eds.), The Heart of Coaching Supervision Oxon: Routledge 
Kamo, J. \& Phillips, F. (1997). The Evolutionary Organization as a Complex Adaptive System. PICMET '97: Proceedings of the Portland International Conference on Management of Engineering and Technology

Kobayashi, V.N. (1988). The Self-Reflexive Mind: The Life's Work of Gregory Bateson. Qualitative Studies in Education, 1(4), 347-359

Lane, D.C. \& Jackson, M.C. (1995). Onlv Connect! An Annotated Bibliography Reflecting and Diversity of Systems Thinking. Systems Research, 12(3), 217-228

Lawrence., P. (2015). Leading Change. How successful leaders approach change management. London: Kogan Page

Lepisky, V. (2018). Evolution of cybernetics: philosophical and methodological analysis. Kybernetes 47(2), 249-261

Malecic, A. (2017). Footprints of General Systems Theory. Systems Research and Behavioral Science Systems Research, 34, 631-636

Marion, R., \& Uhl-Bien, M. (2001). Leadership in Complex Organizations. The Leadership Quarterly, 12(4), 389-418

Miller, J.G. (1978). Living Systems. McGraw-Hill New York

Rousseau, D. (2015). General Systems Theory: Its Present and Potential. Systems Research and Behavioral Science Systems Research, 32, 522533

Schneider, M. \& Somers, M. (2006). Organizations as complex adaptive systems: Implications of Complexity Theory for leadership research. The Leadership Quarterly, 17, 351-365

Schwaninger, M. (2015). Research Paper Model-based Management: A Cybernetic Concept. Systems Research and Behavioral Science, 32, 564-578

Scott, D.C. (2016). Cybernetic Foundations for Psychology. Constructivist Foundations, 11(3), 509-517

Snowden, D.J. \& Boone, M.E. (2007). A Leader's Framework for Decision Making. Harvard Business Review, 85(11), 68-76

Stacey, R. D. (2012). Tools and techniques of Leadership and Management. Meeting the challenge of complexity. Abingdon, UK: Routledge

Stacey, R. D. \& Mowles, C. (2016). Strategic Management and Organisational Dynamics, $7^{\text {th }}$ edition. Harlow, UK: Pearson

Suchman, A. L. (2011). Organizations as Machines, Organizations as Conversations. Two Core Metaphors and Their Consequences. Medical Care, 49(12), S43-S48 
Ulrich, W. (2003). Beyond methodology choice: critical systems thinking as critically systemic discourse. Journal of the Operational Research Society, 54, 325-342

Varela, F. J., Maturana, H. R., \& Uribe, R. B. (1974), Autopoiesis: The Organization of Living Systems, Its Characterization and a Model. Biosystems 5(4), 187-196

Whittington, J. (2012). Systemic Coaching \& Constellations. An Introduction to the Principles, Practices and Applications. London: Kogan Page 